\title{
PURITANOS E REVOLUCIONÁRIOS: as origens da primeira revolução sexual
}

\author{
DABHOIWALA, Faramerz. As origens do sexo: uma história da primeira revolução sexual. \\ Tradução: Rafael Mantovani. 1. ed. São Paulo: Globo, 2013.
}

Wallas Jefferson de Lima*

Palavras-chave: Sexualidade; Revolução Sexual; História Social; Cultura.

Keywords: Sexuality; Sexual Revolution; Social History; Culture.

Palabras Clave: Sexualidad; Revolución Sexual; Historia Social; Cultura.

Pode ser contraditório intitular um livro como As Origens do Sexo quando, na verdade, seu recorte espaço-temporal abarca a Grã-Bretanha do período 1600-1800. De qualquer forma, FaramerzDabhoiwala - professor e pesquisador de História da Universityof Oxford não deseja apresentar uma história linear e "total" da sexualidade, mas descrever as transformações das experiências sexuais do Ocidente, relacionando-as com as grandes propensões políticas, intelectuais e sociais da época. Três elementos estruturais estão na base da composição da obra: o espaço, ou seja, a casa, o bordel, a rua, etc.; os personagens, isto é, os homens e as mulheres; e o elemento unificador: o sexo. Da trama sutil desses fatores, surge uma história enquanto realidade axiomática. A arte de Dabhoiwala consiste, sobretudo, na habilidade com que conseguiu arranjar esses elementos, salvaguardando o caráter multifacetado de análises que não permite o esgotamento das possibilidades interpretativas. $\mathrm{O}$ resultado é a conclusão de que as atitudes em relação ao sexo oscilaram, na Inglaterra dos séculos XVII-XIX, entre a censura tirânica e a relativa liberdade.

O livro é, sobretudo, um grande mosaico crítico de uma cultura que intentava disciplinar a sexualidade, mas que, com o tempo, viu emergir em seu próprio meio ideias relacionadas a uma maior tolerância e liberdade sexual. Texto nascido a partir da análise das mais variadas fontes históricas - Literatura, Tratados Morais, Processos-crime e Legislação

\footnotetext{
* Doutorando do Programa de Pós-Graduação em História da Universidade Federal do Paraná, vinculado a Linha de Pesquisa Espaço e Sociabilidades. Bolsista Capes. Contato: Rua XV de Novembro, 1299, Centro, CEO: 80060-000, Curitiba - PR, Brasil. E-mail: wallasjefferson@ hotmail.com.
} 
encontram-se ajustadas. $\mathrm{O}$ discurso continuamente se entrelaça a uma linguagem poética, em Criminal -, compõe-se de um complexo tecido no qual História, Literatura e Jurisprudência uma investigação histórica sem precedentes. Dabhoiwala propõe uma História da Sexualidade que é, no seu conjunto, uma narrativa sempre reencetada. Por isso, os mais variados assuntos são trazidos à tona - casamento, prostituição, libertinagem, individualismo, ascensão da opinião pública, urbanização, tolerância religiosa, crescimento da cultura de massa, propagação da impressão e filantropia -, constituindo, todos eles, um verdadeiro amálgama de elementos que permitem, cada um a seu modo, que a sexualidade passasse a ser entendida como uma questão privada, de moral pessoal, sujeita apenas ao controle individual. Esta seria, segundo o autor, "a primeira revolução sexual".

O capítulo 1, Declínio e queda da punição pública, explica que até fins do século XVI o policiamento das condutas sexuais era exercido não somente pelo poder da Igreja e do Estado, mas também pela participação popular - vigias, agentes de polícia, pais de família. Tratava-se de um enorme sistema que defendia padrões coletivos de comportamentos sexuais e que por trás dessa vigilância incessante buscava inculcar os ideais de monogamia e castidade, além de condenar práticas como luxúria, fornicação, adultério e prostituição. Fundamenta o autor que prostitutas, adúlteros e sodomitas foram, por muito tempo, ridicularizados, estigmatizados e até mesmo mortos por seus vizinhos e pela comunidade em geral. Essas tentativas de criar uma sociedade livre do pecado - característica da sociedade inglesa puritana - fizeram surgir leis mais rígidas para impor a disciplina sexual. Todavia, deve-se levar em consideração que os padrões exigidos tornavam muitos julgamentos puras ocasiões de formalidade. $\mathrm{O}$ autor considera essa questão uma notável ironia: o poder político e religioso buscava o apelo popular, todavia, a campanha anti-imoralidade surtia o efeito contrário. Isso porque sua retórica dependia de grupos de delatores regulares e oficiais, coisa rara naquele período. Além disso, o crescente tamanho e a complexidade da vida na Inglaterra Industrial minaram a eficácia desse sistema de policiamento sexual. O movimento da população do campo para as cidades, onde havia mais lugares e ocasiões para o ato sexual, acabou por tornar a comunidade em geral menos vigilante em relação aos transgressores. $\mathrm{O}$ anonimato das grandes cidades conseguiu enfraquecer a perseguição a práticas sexuais mais heterodoxas. O resultado foi exatamente um declínio e uma queda da punição pública quando comparados a períodos anteriores.

No capítulo 2, A ascensão da liberdade sexual, o autor explica que a mudança que mais abalou a sociedade entre fins dos séculos XVI e início do XVII foi a cisão religiosa, fato 
que acabou por legalizar a pluralidade moral inglesa. Na verdade, Dabhoiwala quer deixar bem claro ao leitor que a tolerância sexual somente cresceu e se difundiu a partir de uma maior tolerância religiosa. Esta tolerância foi, de fato, uma das características centrais do Iluminismo europeu. Com base nos escritos de variados pensadores, como John Locke, John Milton, David Hume, William Walwyn, Thomas Hobbes, Pierre Bayle, Richard Fiddes, Joseph Priestley e Robert Malthus, o autor elucida como tais filósofos ajudaram a expandir o escopo da liberdade pessoal. Buscavam, com isso, viver em um clima muito mais pluralista. $\mathrm{O}$ efeito das discussões filosóficas foi colocar as normas morais numa posição mais liberal, fazendo surgir, já na década de 1750, uma doutrina considerada bem desenvolvida de liberdade sexual. Sexo era, a partir desse período, uma questão privada. Criou-se um modelo civilizacional baseado nos princípios da "privacidade, igualdade e liberdade", princípios que foram fundamentais para a criação de um novo modelo de cultura sexual e que o Ocidente continua a sentir seus reflexos.

O culto à sedução constitui o capítulo 3. Busca situar o leitor nas novas maneiras de observar o sexo feminino. Antes de 1800, afirma Dabhoiwala, as mulheres eram consideradas o sexo mais lascivo. Argumentos misóginos eram tão difundidos que era ideia comum entre a sociedade de que elas eram mental, moral e corporalmente mais fracas do que os homens. No século XIX ocorre uma mudança radical em relação a essa visão. A partir desse período, a ideia era exatamente oposta: passou-se a acreditar que na verdade eram os homens os seres mais libidinosos por natureza. No caso deles, isso era uma espécie de "impulso elementar". O sexo feminino passará a ser considerado como "delicado", "passivo", "frágil". Segundo o autor, tal mudança estava extremamente avançada na metade do século XVIII, pois já era expressa de forma notória em grandes romances em língua inglesa que surgiram entre as décadas de 1740 e 1750. O interessante é que essa nova visão da premissa da lascívia masculina foi, em grande parte, herdada da crescente proeminência cultural de mulheres artistas. Houve, por exemplo, uma enorme ascensão de atrizes profissionais no teatro inglês após 1660. As peças elisabetanas e jacobinas encenavam a vulnerabilidade feminina sempre contrastada com a lascívia masculina. A violência masculina tornou-se o tema central de vários enredos trágicos. Peças de comédia como Rei Lear, escrita por Nahum Tate, VertueBetray'd, de John Banks, The Orphan, de Thomas Otway, e The Fair Penitent, de Nicholas Rowe, apenas para citar algumas, colocavam o sofrimento feminino no centro da história. Eram claras admoestações contra as artimanhas dos homens que colocavam em cena, quase sempre, estupros, raptos, enganações e mortes. O romance foi outro meio utilizado para 
divulgar essa imagem de "sexo frágil" em relação à mulher. Conquista e sedução eram assuntos primordiais no romance, como o comprovam as obras de Jane Austen, AphraBehn, DelarivierManley e Eliza Haywood, PenelopeAubin, Jane Barker e Mary Davys. Essas autoras ajudaram, cada uma a seu próprio modo, a estabelecer o romance como a forma mais difundida de literatura inglesa, sendo a sedução - e questões como o amor, conquista e desejo carnal - seu enredo mais fundamental. Dabhoiwala acredita que o romance teve, nesse contexto, um papel fundamental na mudança para uma moralidade mais tolerante.

Em O novo mundo de homens e mulheres, quarto capítulo da obra, o autor explica que a imagem do homem voraz sexualmente fez emergir uma outra imagem: a das mulheres que, do século XIX em diante, deveriam se resignar, se fechar, se enclausurar cada vez mais para proteger-se das investidas masculinas. O que estava em causa, após as primeiras décadas do século XIX, era como domar a imprudência e a aparente promiscuidade "natural" do macho. Essa ideia de que as mulheres eram superioras moralmente tinha uma força gigante. Isso acabou por dividir a suposta natureza sexual dos homens e das mulheres, legitimando e acentuando preconceitos sociais e sexuais, preconceitos estes que ainda hoje se fazem presentes. Diante disso, a questão posta aos homens do período foi a seguinte: como canalizar a lascívia masculina de modo a preservar a "pureza" feminina? A resposta a essa pergunta estava, entre outras coisas, na aceitação social da prostituição. Entendia-se que melhor seria reservar uma classe de mulheres "inferiores" do que sacrificar as "respeitáveis".

Diante disso, o quinto capítulo, As origens da escravidão branca, dedica-se a explicitar a posição social das prostitutas no seio da sociedade britânica no século XIX. Segundo o autor, foram realizados diversos esforços no intuito de criar abrigos, workhouses e instituições de caridade (como a MagdalenHousee a LamberthAsylum) para as mulheres "decaídas" e garotas em risco de sedução ou vítimas potenciais da lascívia dos homens. Por trás da configuração filantrópica pública em prol das meretrizes havia, porém, diversos interesses egoístas. Crescia a visão de que o encarceramento rotineiro e a exploração econômica dessas mulheres não passavam de meios para transformá-las em membros economicamente produtivos da sociedade.

O sexto e último capítulo, Os meios e a mensagem, narra como a revolução midiática do Iluminismo - exemplificada pelo crescimento da cultura de massa, da pornografia, de publicações biográficas de prostitutas e cafetinas, de xilogravuras baratas e de gravuras das "damas de prazer" - foi central para as mudanças comportamentais em relação ao sexo no século XIX. O crescimento da mídia, a disseminação dos livreiros, o aumento do número de 
alfabetizados, a ascensão da imprensa periódica como os jornais e o maior uso de panfletos na sociedade fizeram emergir uma cultura midiática que ajudou a criar um novo modelo de vivências erótico-sexuais no Ocidente. Criaram-se, por exemplo, diversos clubes especiais masculinos como o Beggar'sBeninson, em que seus membros reuniam-se para beberem, conversarem acerca de sexo e, em alguns momentos, ejacularem coletivamente lendo pornografia. O prazer sexual passou a ser celebrado em fins do século XIX. Houve, segundo o autor, uma espécie de colapso do policiamento sexual. Desenvolveu-se uma enorme indústria material dedicada ao sexo. A prostituição tornou-se mais visível. Pinturas, desenhos e livros eróticos eram sensação quase instantânea, popularizando-se no mundo anglófono. Amplamente relidos, tais imagens e textos ajudaram a apressar o desenvolvimento da vida privada. O resultado foi o aumento de um público ávido por leituras desse tipo, muito mais amplo do que nos séculos precedentes, refletindo uma nova apreciação do homem moderno com o ato sexual.

No epílogo, Culturas modernas do sexo - dos Vitorianos até século XXI, Dabhoiwala destaca os temas e recortes que utilizou para explicar as origens das atitudes modernas ocidentais em relação ao sexo. Afirma que não se pode estudar a História da sexualidade sem compreender as revoluções sociais que abalaram o Ocidente, especialmente as do século XVIII.

O livro, portanto, não é autotélico: volta-se para alvos definidos, com existência própria. De modo geral, em toda a obra verifica-se uma vinculação íntima entre o passado legível e o presente oculto. Sem dúvida, os historiadores estão diante de uma obra que ainda tem muito a revelar. O que surge ao longo das páginas é o homem moderno, moldado pela cultura em corte profundo. Dabhoiwala realizou um notável trabalho, tendo que trilhar por um caminho difícil, pois enveredou por um campo de pesquisa mais ou menos ilimitado. Para seu crédito, o autor abraça as complexidades dos estudos históricos, escrevendo de maneira clara e sucinta. A escrita dessa obra pôs em relevo a transgressão sexual, à margem das grandes cidades inglesas entre os séculos XVIII e XIX, resgatando o sentido do caráter infrator do sexo que prefigurou, a seu modo, a maneira como a sexualidade é vivida na contemporaneidade. 